\title{
Establishment of a catchment monitoring network through a participatory approach in a rural community in South Africa
}

\author{
V. M. Kongo ${ }^{1, *}$, J. R. Kosgei ${ }^{1, * *}$, G. P. W. Jewitt ${ }^{1}$, and S. A. Lorentz ${ }^{1}$ \\ ${ }^{1}$ School of Bioresources Engineering and Environmental Hydrology University of KwaZulu-Natal, PB X01, Scottville, \\ Pietermaritzburg, South Africa \\ *now at: Stockholm Environment Institute-Africa Centre, Institute of Resource Assessment, University of Dar es Salaam, \\ P.O. Box 35097, Dar es Salaam, Tanzania \\ ** now at: Masinde Muliro University of Science \& Technology, Department of Civil \& Structural Engineering, \\ P.O. Box 190-50100, Kakamega, Kenya
}

Received: 10 September 2007 - Published in Hydrol. Earth Syst. Sci. Discuss.: 16 October 2007

Revised: 10 November 2010 - Accepted: 22 November 2010 - Published: 13 December 2010

\begin{abstract}
The establishment of a catchment monitoring network is a process, from the inception of the idea to its implementation, the latter being the construction of relevant gauging structures and installation of the various instruments. It is useful that the local communities and other stakeholders are involved and participate in such a process, as was highlighted during the establishment of the hydrological monitoring network in the Potshini catchment in Bergville District in the KwaZulu-Natal Province, South Africa. The paper highlights the participatory establishment of a hydrological monitoring network in a small rural inhabited catchment, in line with the overall objective of the Smallholder System Innovations (SSI) research programme, to monitor hydrological processes at both field and catchment scale for water resources management research purposes. The engagement and participation of the Potshini community precipitated a learning opportunity for both the researchers and the local community on (i) the understanding of hydrological processes inherent in the catchment (ii) appreciating the inherent dynamics in establishing a catchment monitoring network in the midst of a community (iii) paradigm shift on how to engage different stakeholders at different levels of participation. The participatory engagement in the monitoring process led to appreciation and uptake of some of the research results by the Potshini community and ensured continued support from all stakeholders. This paper is of the view that the participation of the local community and other stakeholders in catchment monitoring and instilling a sense of ownership and
\end{abstract}

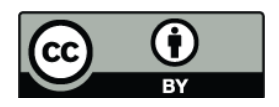

Correspondence to: V. M. Kongo (vickongo@gmail.com) management of natural resources to the local communities needs to be encouraged at all times. Success stories in water resources management by local communities can be realized if such a process is integrated with other development plans in the catchment at all forums, with due recognition of the social dynamics of the communities living in the catchment.

\section{Introduction}

Sound decision making for water resources and environmental management has to be based on good knowledge and factual information regarding the dominant hydrological processes, together with bio-physical characteristics of a catchment and in combination with socio-economic aspects. Such information, especially on hydrological processes, can only be obtained through establishing networks that are capable of monitoring hydrological processes at different temporal and spatial scales. Such a process is normally driven by a motive to meet certain research objectives (e.g. Wigmosta and Burges, 1997; Gilvear and Bradley, 2000; Hodgson et al., 2002; Ireson et al., 2006), but with consideration of the cost implications with regard to construction and acquisition of the various instruments and their maintenance. However, research catchments are typically established in uninhabited areas. In fact, people are usually excluded from such catchments as they add uncontrollable variables to the experiment as well as present the risk of theft and vandalism.

An alternative perspective is that the establishment of a catchment monitoring network involves a process, from inception of the idea to the actual construction of the various structures and installation of the necessary equipment and

Published by Copernicus Publications on behalf of the European Geosciences Union. 
instruments while engaging relevant stakeholders, but that this forms only the first few steps of an ongoing engagement with the community. This perspective has become increasingly important in the context of initiatives to ensure food security at the household and smallholder level where detailed understanding of water dynamics is imperative, but largely unknown. From the farmer's perspective, to decide that a water use innovation is worthy of investment, they also need a realistic understanding of its risks and benefits, including factors such as time and monetary input requirements, but very importantly, potential effects on yield and soil and water conservation. This reduces the risk of wasted expenditure on an innovation that is not suited to their specific situation, which could lead to reluctance towards trying other potentially beneficial innovations (Sturdy et al., 2008). In order to realize these benefits, the involvement of the smallholder farmers from the onset is imperative.

There are few case studies in the available literature on the establishment of detailed catchment monitoring networks through a participatory approach involving the local community and other stakeholders. Moriarty (2000) reported the establishment of the Romwe catchment in Zimbabwe through the involvement of the local community, but the participatory approach that was applied in due process was not highlighted. A survey study by Loreta et al. (2006) indicated the desire by local communities and other stakeholders to be involved in water quality monitoring and surveillance in the Mzingwane catchment in Zimbabwe, even though they were not aware of the existence of such a monitoring programme in their locality.

It is perceived that the participatory approach in catchment monitoring has long term benefits, including the opportunity for the relevant stakeholders, notably the local community, to gain insight into the hydrological regime of their locality. This in turn provides a better basis for decision making for catchment based activities and understanding the impact of anthropogenic activities on water resources in the catchment, thus contributing to environmental education. The latter is key to effective community involvement in participatory research and development of research products that are relevant and acceptable to the community (Marshke and Sinclair, 2009). Thus, a participatory approach requires a constant effort to initiate a learning process, through which the local community is able to appreciate and recognize the importance of catchment monitoring, notwithstanding the willingness of the community to participate in the monitoring exercise.

This paper highlights the participatory establishment and monitoring of a hydrological network in the midst of a rural community, the Potshini community, in the upper Thukela river basin in South Africa. The catchment monitoring network was established in line with the overall objective of the Smallholder System Innovations (SSI) in integrated watershed management research programme (Rockström et al., 2004) of addressing the challenges of increasing food production and improving rural livelihoods while safeguarding critical ecosystem functions and services. The approach used to establish the monitoring network supports the contention of Wagener et al. (2010) that a key element of a "paradigm shift" in our approach to understanding the hydrological functioning of coupled human-nature systems is to move from a perspective of humans being intrinsic, rather than external to the hydrologic system and to research catchments which are not pristine, but rather reflect the places where humans live and interact. Thus, the paper provides a good case study for considering the many issues and challenges (social, scientific and engineering) that need to be addressed in the process of establishing the monitoring network in a populated rural catchment in a developing region. The paper shares experience which is often not documented in literature, but of great value in water resources management, especially in developing countries.

\subsection{The study area}

The Potshini catchment, Figs. 1, 2 and 3, is located in the foothills of the Drakensberg mountains in South Africa $\left(29.3679^{\circ} \mathrm{E}, 28.8145^{\circ} \mathrm{S}\right)$ at an average altitude of $1310 \mathrm{~m}$ and is predominantly a smallholder farming area and a subcatchment of the Quaternary Catchment ${ }^{1}$ number V13D (Emmaus catchment) in the Thukela River basin in South Africa. The Thukela river basin is comprised of 86 Quaternary Catchments with a total area of $29036 \mathrm{~km}^{2}$, with the Quaternary Catchment V13D having an area of $285 \mathrm{~km}^{2}$. The Potshini catchment comprises 2-nested catchments, with an area of $1.2 \mathrm{~km}^{2}$ (gauged by an H-Flume) and $10 \mathrm{~km}^{2}$ (gauged by a pressure transducer), respectively (cf. Figs. 1 and 3). The mean annual precipitation at Potshini is estimated to be $700 \mathrm{~mm} \mathrm{a}^{-1}$ and the estimated mean annual potential evaporation is between 1600 to $2000 \mathrm{~mm} \mathrm{a}^{-1}$ (Kongo and Jewitt, 2006). The rains occurs during the summer season (September to April), with heavy rains being characterized by thunderstorms and occasional hailstorms.

The maximum and minimum temperatures recorded in the catchment since 2004 are 34 and $-4{ }^{\circ} \mathrm{C}$ respectively. Frost is common during the dry winter season (May to August) and has often destroyed vegetative materials in the catchment, including vegetables in homestead gardens. Due to local topography and high summer rainfall, a good drainage network has developed in the Potshini catchment with some of the streams being perennial and providing water for domestic use to the upper part of the catchment, while replenishing reservoirs for commercial farmers downstream. The main land uses in the catchment include the predominant smallholder farming (crop production) during summer, which constitutes approximately $60 \%$ of the total land in the catchment,

\footnotetext{
${ }^{1}$ Quaternary Catchments (QC) in South Africa are the smallest delimitations of a river basin upon which policies and decision with regard to water resources management are based upon. The QC were defined and established by the National Department of Water Affairs and Forestry.
} 


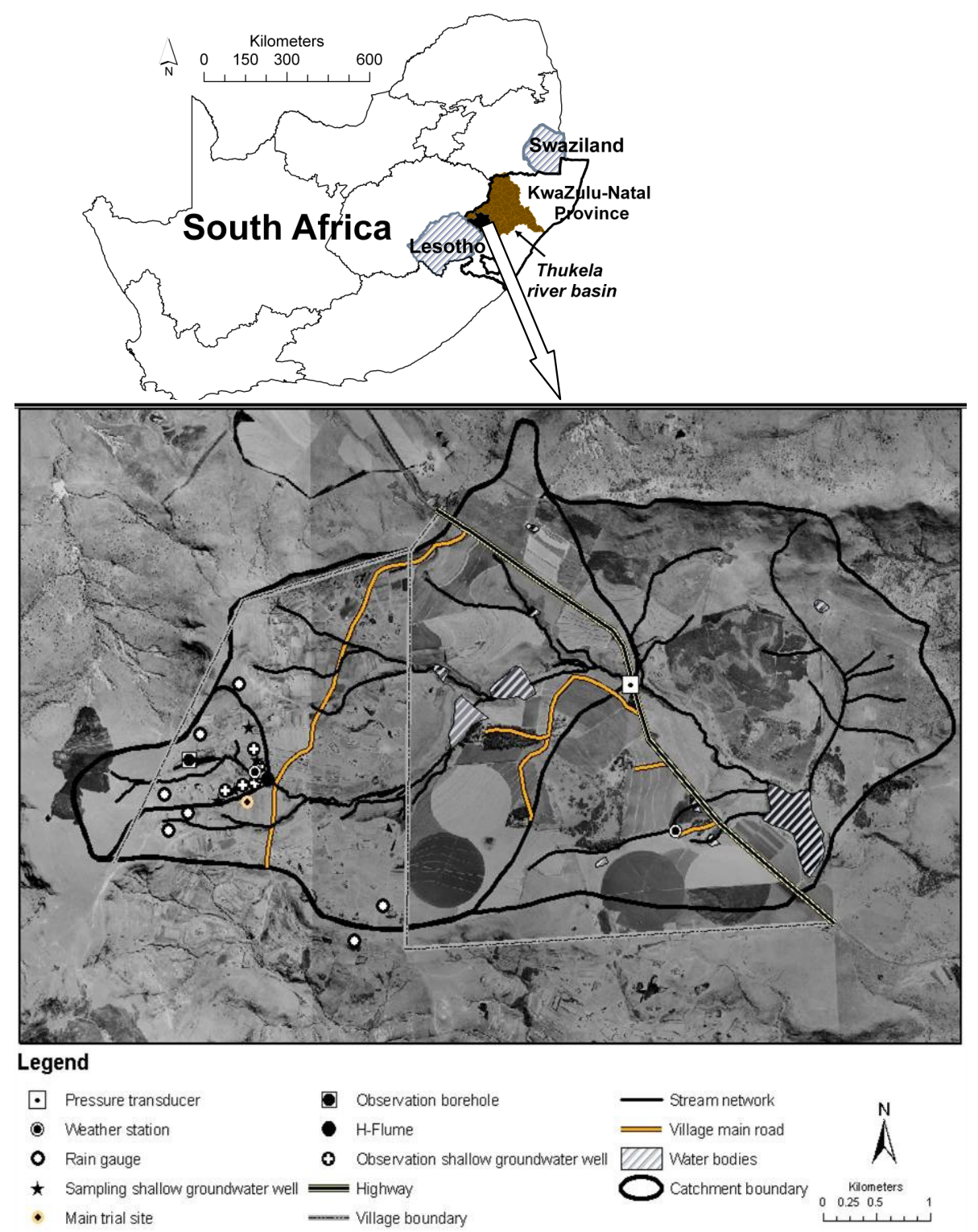

Fig. 1. An overview of the Thukela River basin and the nested Potshini catchment.

and grazing. The smallholder farms are individually owned while grazing areas and boreholes that were installed by the local authorities are considered common property. The main sources of water for domestic use in the community are bore holes, springs and the Potshini stream.

\section{Objectives for establishing the Potshini catchment monitoring network}

The inclusion of people in research catchments has many challenges. Nevertheless, one cannot carry out convincing studies on the interaction between water resources and food security of any rural community without considering the livelihoods of the rural community and the dominant hydrological processes taking place in the locality. It is with this understanding that the Potshini catchment monitoring network was established, to address some of the scientific and developmental objectives of the Smallholder System Innovations programme. The main objectives of establishing the Potshini catchment monitoring network were:

- Monitoring the hydro-climatological processes of the Potshini catchment in order to gain an in-depth understanding of the hydrological regime of the catchment and investigate the hydrological and ecosystem impacts of adoption and adaptation of water use innovations (e.g. rainwater harvesting, conservation tillage etc.) in the Potshini catchment. 


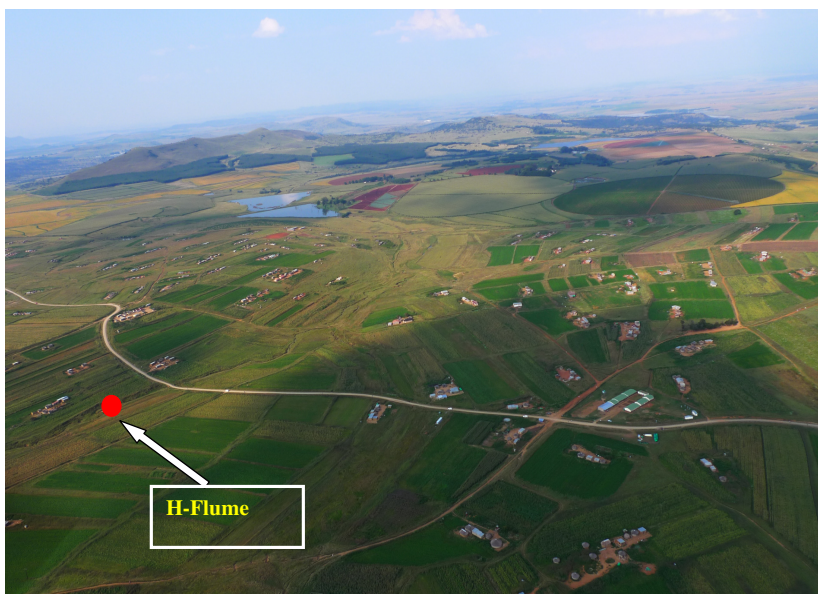

Fig. 2. An overview of the households in the Potshini catchment.

- Establishing a capacity to assess, monitor, and manage water and environmental resources in the Potshini community in collaboration with various stakeholders through training on the basic methodologies of catchment monitoring.

- Providing information to scientists and community members alike on the potential for improved productivity from water resources of the catchment.

- Providing an opportunity for future and further research through the establishment of a catchment monitoring network with a potential for upscaling and integrating into other larger networks in the country. This is due to the fact that the network comprises several permanent structures which other researchers may use in their studies in the future after the completion of the SSI research programme ${ }^{2}$.

The SSI research programme was focused on investigating the potential of small-scale water system innovations for upgrading rainfed farming in semi-arid agro-ecosystems, including aspects such as the need for local adaptations of these techniques, adoption of them among smallholder farmers and possible trade-offs between water for agriculture and water for surrounding ecosystems. It must be noted that SSI was both a scientific programme and as such dedicated to the delivery of innovative and high quality research, albeit in a developmental setting, as well as a development and outreach programme, dedicated to the improvement of human livelihoods through the application and uptake of water system innovations (Sally, 2010). The instrumentation which formed the Potshini hydrological monitoring network ranged in sophistication from simple manual rain guages, to state of the art instruments such as the Large Aperture Scintillometer.

\footnotetext{
2 an aim which is being achieved through ongoing research initiative
}

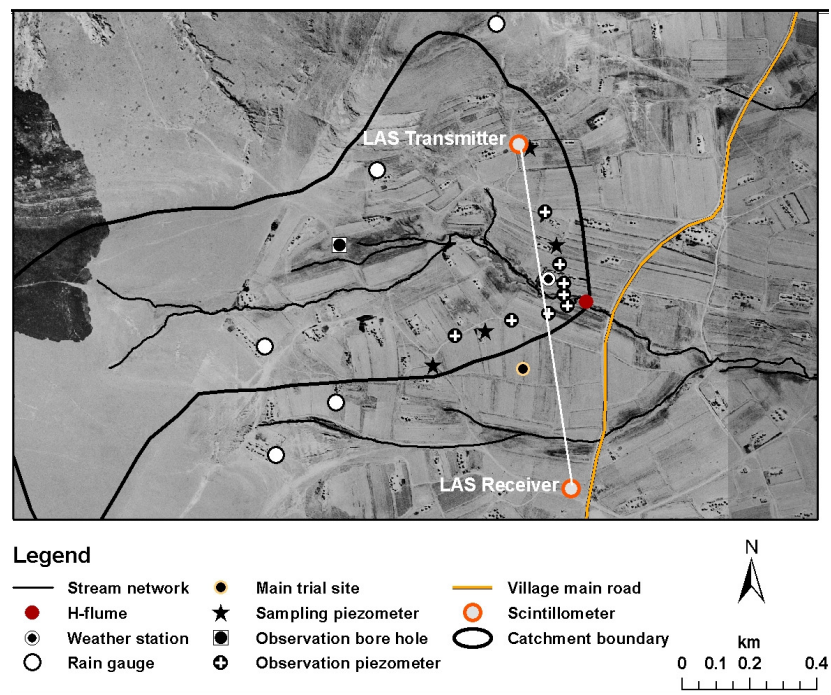

Fig. 3. The $1.2 \mathrm{~km}^{2}$ Potshini catchment.

\subsection{Main stakeholders}

The process of establishing the Potshini catchment monitoring network was initiated in early 2004 under the SSI research programe at the School of Bioresources Engineering and Environmental Hydrology of the University of KwaZuluNatal, South Africa. The process integrated two approaches (i) a participatory approach where the local community and other stakeholders were involved and participated and (ii) a scientific approach which entailed the application of scientific and engineering principles in designing, construction and installation of various structures and instruments. The two approaches were not treated separately but rather formed an integrated continuous learning process where the relevant stakeholders and researchers made an effort to interact and to learn from each other. The main stakeholders for the SSI programme in the Potshini catchment, at various degrees of participation, included the following: (i) smallholder farmers actively participating in various experimental and monitoring activities (ii) members of the local community in the Potshini catchment in observation and construction; (iii) smallholder farmers neighbouring the Potshini catchment in attending field days and learning sessions; (iv) neighbouring large scale commercial farmers in participating and supporting the catchment monitoring initiative; (v) the traditional and local leadership in assembling and motivating the community; (vi) the Provincial Department of Agriculture and Environment in supporting teaching, providing material inputs, organizing field days and encouraging the community to become involved; (vii) the Agricultural Research CouncilInstitute of Climate Soil and Water in contributing expertise from past research in Potshini; (viii) the Local Authority-the Okhahlamba Municipality in encouraging the community to become involved and providing material inputs and (ix) the 
KwaZulu-Natal Provincial Department of Water Affairs and Forestry in providing monitoring and domestic boreholes.

The Potshini catchment was previously ungauaged and the catchment monitoring network already has provided benefits to both the local community on the upstream (as elaborated in subsequent sections of this paper) and to the downstream water users, e.g. the commercial farmers who rely on the water yields from the upper Potshini catchment for replenishing their farm dams (cf. Figs. 1 and 2). Any change in land use or water use, e.g. intensification of rainwater harvesting on the upper catchment could significantly affect the catchment response, including water quality e.g. sediment load, which is an important parameter with regard to management of the downstream reservoirs. It is also acknowledged that the water quality of the water filling the downstream reservoirs could be impaired due to the anthropogenic activities on the upstream, e.g. washing clothes in streams using phosphorous-enriched detergents and intensive application of fertilizers on the smallholder farms in the community. Thus, the downstream water users were also important stakeholders in the hydrological research undertakings in the SSI research programme.

The Potshini catchment monitoring network comprised gauging structures and instrumentation, mostly automated, for measuring and monitoring stream flows, overland flow from experimental runoff plots, sediment load, shallow and deep ground water bodies, subsurface resistivity using Electrical Resistivity Tomography (Loke, 2003), isotopic composition (Deuterium and Oxygen-18) in both surface and subsurface water, volumetric soil moisture content dynamics, soil hydraulic characteristics, crop transpiration rates and meteorological variables. The application of scintillation techniques (Large Aperture Scintillometer) in estimating total evaporation in the Potshini catchment formed an intermediate observation and a local-scale calibration for remote sensed estimates of total evaporation from satellite images in the catchment and the Thukela river basin at large, using the Surface Energy Balance Algorithm for Land (SEBAL) (Bastiaanssen et al., 1998a,b; Bastiaanssen, 2000). Initial results on hydrological studies based on data obtained from the Potshini catchment monitoring network are reported in Kongo and Jewitt (2006), Kosgei et al. (2007) and Kongo et al. (2010). In addition, various experiments in crop water use and land preparation were conducted where farmers were directly involved in assessing different land preparation and crop production techniques at field scale. Here, the research team provided detailed measurements of soil hydraulic characteristics and monitoring crop water use in close collaboration with the owner/smallholder farmer who kept detailed records of application and yield.

\subsection{Overview of a logical hydrological measurement sequence}

Although hydrological processes vary continuously in time and space, they are often described and derived from point measurements. The resulting data form a time series, which is typically subjected to further processing, including statistical analysis and or hydrological modelling. Chow et al. (1988) highlighted a sequence of logical steps which are commonly followed for hydrological measurements and monitoring, beginning with the instrumentation of a physical device that senses or reacts to the physical phenomenon and ending with the delivery of data to the users. Such a sequence was adapted during the establishment of the Potshini catchment monitoring network with an additional participatory component where the input from the local community and other stakeholders was sought and incorporated as indicated in Fig. 4. In the absence of the participatory component, the sequence describes a scenario which is biased to understanding the hydrological processes in a catchment, but void of the social dimension of how the local community understand and respond to the hydrological processes being monitored. The social dimension is valuable for several reasons, including (i) the understanding by the researchers of the community's knowledge base with regard to the dominant hydrological processes e.g. rainfall patterns, stream flows, temperatures etc.; (ii) creation of a platform for the community to learn more in quantifiable terms about the dominant hydrological processes taking place in their midst and the importance of understanding such processes and (iii) facilitation and enhancement of the community's willingness to invest time and effort in the monitoring activities, not withstanding their goodwill in maintaining and securing the various equipment and instruments in their midst.

An example of application of the local knowledge base in this study is highlighted in Sects. 3.2 and 3.3 of this paper. Such an approach perpetuated a sense of ownership and, through interaction with the SSI researchers, imparted management skills of natural resources to the local community. The social dimension can be complicated if several stakeholders with diverse interests are involved in the establishment of a catchment monitoring network. Nevertheless, such diversity can be a source of inspiration and strength if a common understanding is sought at the initial stages. However this must be based on good working relationships and trust, of which was achieved during the establishment of the Potshini catchment monitoring network as explained in Sect. 3. Although the steps indicated in Fig. 4 may appear to be obvious, even simple, they need to be followed and documented for the purpose of sharing the experience and knowledge as highlighted in this paper. 


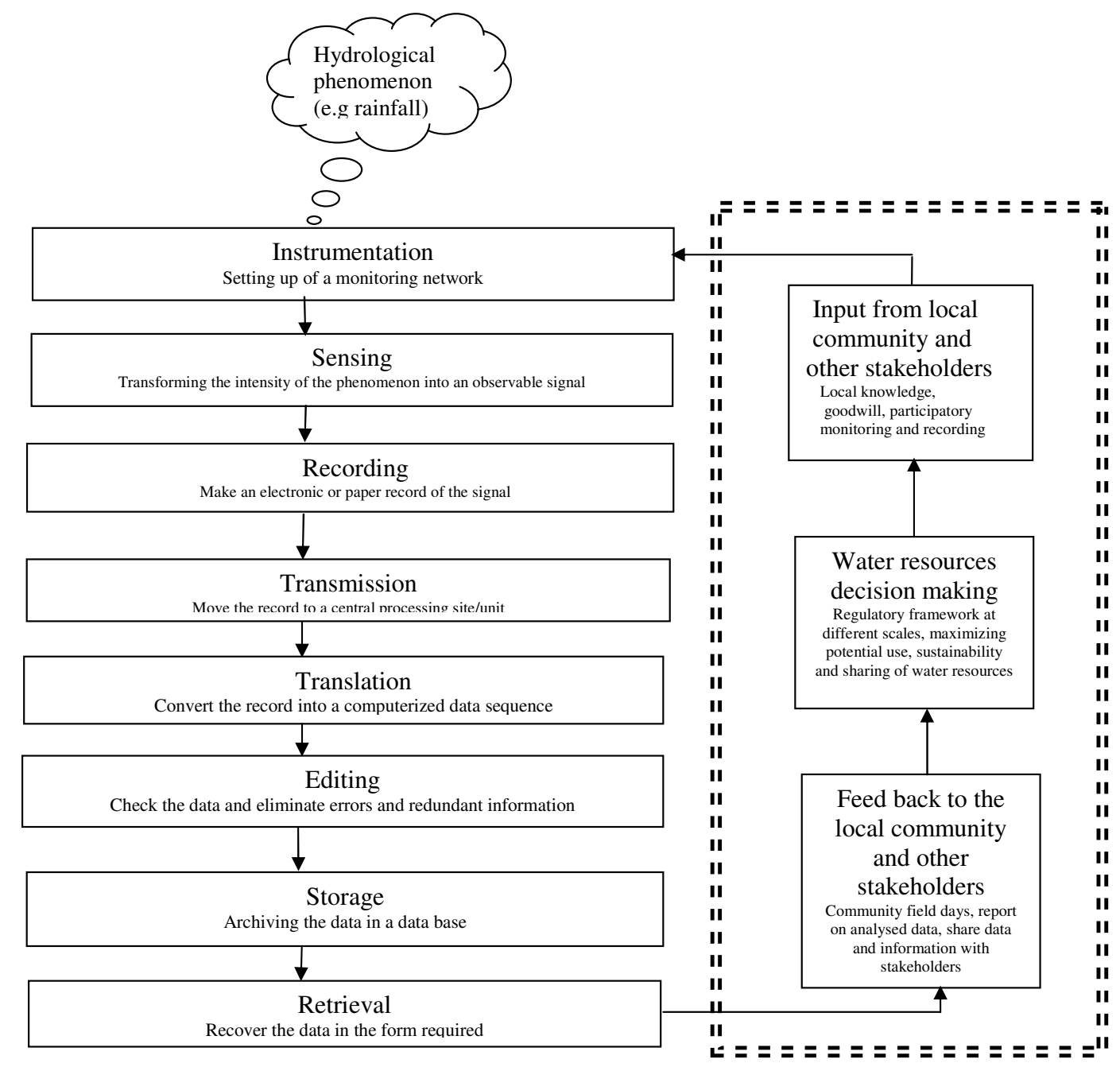

Fig. 4. Hydrological measurement sequence with a participatory component indicating the role of the local community and other stakeholders.

\section{Monitoring network establishment}

\subsection{The participatory process}

A communication process and dialogue was initiated between the researchers and the relevant stakeholders in the catchment and the research approach applied in establishing the Potshini catchment monitoring network followed a Participatory Research approach (Bhatt et al., 2006), where the smallholder farmers and other stakeholders were involved from the initial preparatory stages to the actual construction and instrumentation of the various structures and instruments and thereafter actively participated in the monitoring.

Local input was sought regarding the siting of structures and instruments and permission to develop a monitoring network was sought from the local farmers' forum, individual farmers as well as from the traditional and local leaders of the area. Local artisans and masons were purposely involved in construction of various structures and installation of some of the instruments as part of a wider learning platform and technology transfer to enable them appreciate the operational mechanisms of the network. The procedure used to select these artisans and masons is highlighted in Sect. 3.3. The culture and practices (e.g. abstaining from any field activities that involve digging or excavation of the soil during burials) of the Potshini community were respected at all times both during and after the establishment of the Potshini catchment monitoring network. The approach proved to be effective in perpetuating a conducive environment for interacting with the local community and hence the goodwill of the community to safeguard any installations in the area. Several smallholder farmers in the Potshini community volunteered to participate in various research activities including managing experimental trials on their farms. The voluntary catchment monitoring by some of the smallholder farmers in the Potshini catchment was beneficial to them as elaborated in Sects. 3.6 and 3.7 of this paper. 
The local community continued to be a key stakeholder in the SSI research programme and an effort was made towards creating and maintaining a cordial relationship with the community based on respect, trust and friendship, an aspect which is expanded upon in Sect. 4 of this paper.

\subsection{Siting of stream flow gauging structures}

The establishment of the Potshini catchment monitoring network involved the initial stage of reconnaissance surveys to gain a general understanding of the catchment before detailed and specific site surveys were performed as per requirements of each structure or instrument. The siting of the stream flow gauging sites and design of the gauging structures in the Potshini catchment involved the application of the local knowledge, scientific and engineering techniques. In particular, the local knowledge on the historical peak flows and flood prone areas was vital during the design and construction of one of the stream flow measuring structures, i.e. an H-Flume, where community members, especially the elders, were involved in some of the reconnaissance surveys in the catchment with regard to siting for an appropriate section along the stream for its construction. For example, the elders were asked how often the stream in the Potshini catchment overtopped its banks and whether the sites that had been identified as ideal for constructing the $\mathrm{H}$-flume, based on the criteria highlighted in Kongo et al. (2007), were safe from flooding and inundation. According to the elders, the site where the H-flume was eventually constructed was prone to inundation at most every three years and they even marked the inundation extent for flooding event at this section as indicated in Fig. 5. This information was useful in the design of the $\mathrm{H}$-flume, especially the orientation of the instrumentation house as discussed in Sect. 3.3 of this paper.

Even though the stream-section on which the H-flume was constructed was prone to inundation (based on local knowledge), it was preferred due to the structural stability of its narrow banks, presence of underlying rocky material for stability of the approach channel, and most importantly enough bed slope for preventing downstream inundation, which is an important parameter in construction of $\mathrm{H}$-flumes (Ackers et al., 1978). It is interesting to note that the information obtained from the local community with regard to historical peak flows (cf. Fig. 5), i.e. stream flow depth during historical peak flows, was in close agreement with results obtained from a modeling exercise, using the Soil Conservation Services (SCS) methodology (Schulze et al., 1992), in determining peak floods from the Potshini catchment.

\subsection{Design and construction of the H-flume}

The main reason for using an $\mathrm{H}$-flume rather than a weir in the $1.2 \mathrm{~km}^{2}$ Potshini catchment was to facilitate accurate monitoring of the sediment load and low flows. The flume was designed to carry a maximum flow of $3.4 \mathrm{~m}^{3} / \mathrm{s}$ at a depth

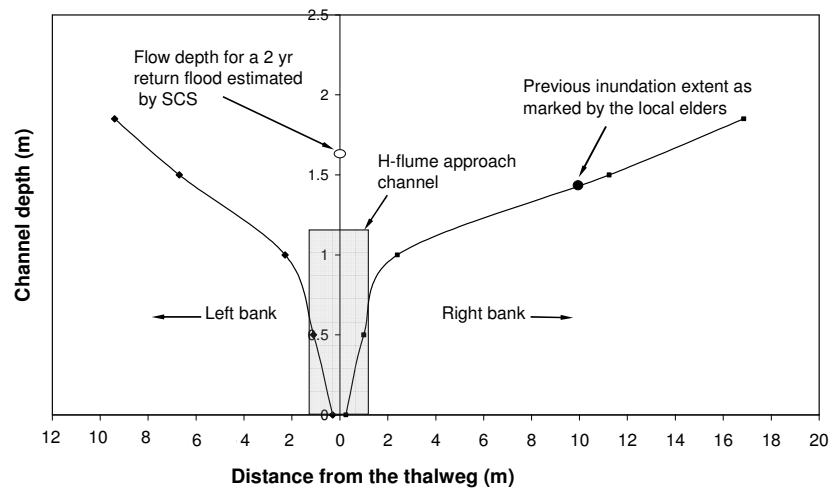

Fig. 5. Schematic diagram of the cross section at the H-flume gauging site (with a vertical exaggeration). See Figs. 1 and 2 for location.

of $1.2 \mathrm{~m}$. Necessary precautionary features and safety factors, together with advice and knowledge from the local people, were incorporated in the design and construction of the instrumentation house and the approach channel to allow the safe passage of a 2-year return period flood without affecting its structural stability. In particular, the orientation of the H-flume's instrumentation house was influenced by the local knowledge from the elders of the Potshini community on inundation extent at the site where the gauging structure was constructed as illustrated in Fig. 5.

The H-flume was constructed with active participation of the local Potshini community, where the local leaders were asked to identify the suitable masons in the community based on the quality of their past workmanship, especially in building brick/block houses in Potshini and surrounding communities. It turned out that three masons had unique experience in certain construction aspects, e.g. foundation, concrete works etc. and hence the SSI research team found it prudent to involve the three as the lead technical team in construction of the H-flume and asked them to find four other persons from different parts of the community to provide labour. Such an approach perpetuated a sense of cohesiveness and team work to the construction team and which turned out to be beneficial after the construction works under the SSI research programme where the same team continued to procure local tenders for construction of both traditional (grass thatched with mud walls) and permanent (block walls with galvanized or tile roofing) houses in the Potshini community, neighbouring communities and the nearby Bergville town.

The contract between the SSI research programme and the local construction team was negotiated on provision of labour, of which the construction team was to construct the $\mathrm{H}$-flume, from foundation to the superstructure within a specified time, while the SSI programme was to provide material and technical expertise on the layout and ensured that all specifications of the structure was as per design. It was a challenge for the construction team to estimate their labour cost given the fact that they had never constructed a similar 
structure before and above all it was to be built in a flowing stream. In this regard, the SSI researchers sought to know the cost of constructing a house in the community, using the same number of building blocks as the $\mathrm{H}$-flume, and added $30 \%$ of such a cost to take care of the extra labour input that was to be required especially in excavation and reinforcement works. In all, the total cost of constructing the H-flume, in 2004, was approximately US\$4000.00, with the labour cost constituting $32 \%$ of the total cost i.e. US\$ 1300.00 .

The local construction team portrayed impressive skills, from reading an engineering design drawing to brick and reinforcement works. The SSI researchers managed to point out in advance the few construction errors that were observed, and which were corrected accordingly. Figure 6 shows the construction of the H-flume in progress. Significantly, the construction team appreciated some important procedures and skills that they learnt during the construction exercise, including the importance of precision in measurements, timeliness and above all their ability to construct a hydraulic structure in a flowing stream, an endeavor they had not undertaken before. Such skills were beneficial later to some members of the construction team when the same team was contracted later in 2005 and 2006 to construct subsurface rainwater harvesting tanks in the community by the SSI researchers and another community development project in Potshini, funded by the Water Research Commission (WRC) of South Africa. One of the criteria that was used to recruit the construction team members in constructing the tanks was their previous experience, which had been demonstrated by those who had constructed the H-flume.

\subsection{Monitoring stream flow}

Stream flow at the larger $10 \mathrm{~km}^{2}$ nested Potshini catchment (cf. Fig. 1) was gauged by monitoring the stage water level fluctuations, at a road culvert, using a pressure transducer. A rating curve was developed at this road culvert gauging site after carrying out velocity transect surveys, using a propeller current meter, on discrete days between 2005 and 2007 and for different discharges. Some members of the Potshini community voluntarily participated in the discharge measurement exercise and benefitted from an understanding of the various controls on streamflow in the catchment. For example, the flows at the culvert bridge are controlled by the upstream farm-dams (cf. Figs. 1 and 2) and most often the flows that are observed at this section are low flows with limited sediment loads and hence there was no need to monitor sediment fluxes at this point except for stage measurements. Level of discharge at the Potshini H-flume (cf. Figs. 1, 2 and 3) was monitored via a tube, connecting the open approach channel discharge to a stilling well as illustrated in Fig. 7.

The Potshini community was also involved in the ongoing monitoring. Every Monday of each week, and after a rainfall event, a designated community member, who was also

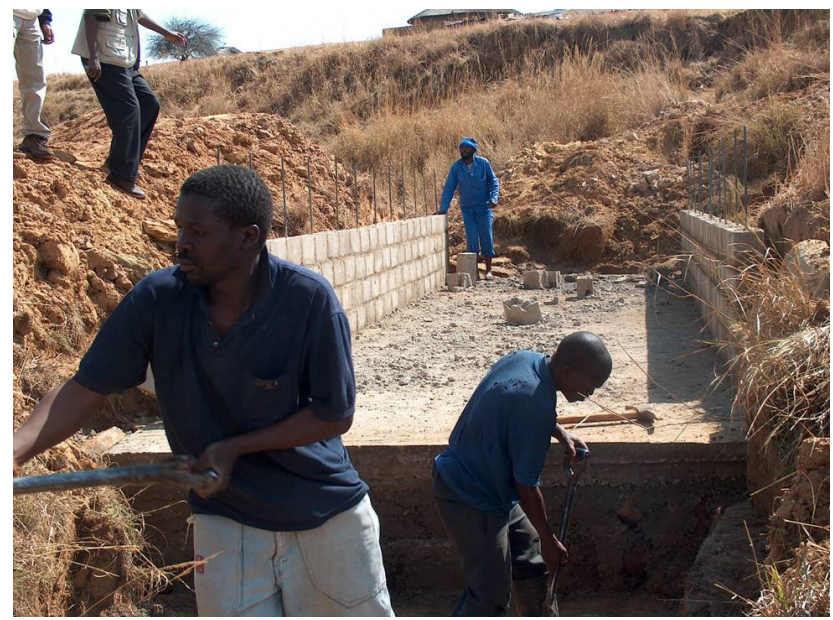

Fig. 6. Constructing the H-Flume in the Potshini catchment.

the SSI programme facilitator in the community, took manual readings of the depth of flow, date and time at the $\mathrm{H}$ flume gauging site using a stainless steel tape measure. It is useful to note that the community facilitator was elected by the Potshini community in a well attended community meeting, to assist or facilitate the SSI researchers on behalf of the community, during the initial stages of implementing the SSI programme. The manual measurements were used to check the stage readings recorded by the data logger. It was interesting and encouraging to note that the community facilitator urged his fellow community members, especially those who had manual rain gauges installed in their homesteads, (Sect. 3.6), to accompany him to the H-flume gauging site when taking the stage readings. This had the benefit of making them aware of the quantifiable relationship between rainfall, which they were recording at their homesteads, and the stream flow recorded at the H-flume. Only the community facilitator was compensated for his continuous monitoring efforts; all the other community members participated in the monitoring activities in the SSI programme out of their interest and goodwill.

\subsection{Monitoring of sediment load and isotopic composition of stream flow}

It is always a challenge to obtain a representative water sample in streams at the desired time and hydraulic conditions, for analytical work on water quality. This is compounded by the fact that stream flows emanating from head water catchments of relatively small area in semi-arid areas are highly variable, with rapid overland flows and interflows (Kongo, 2008). Thus a good sampling scheme should take into consideration such variations of flow by taking frequent samples during a changing flow.

Two parameters, i.e. sediment load and isotopic composition of Oxygen-18 and Deuterium $\left({ }^{18} \mathrm{O}\right.$ and $\left.{ }^{2} \mathrm{H}\right)$ were 


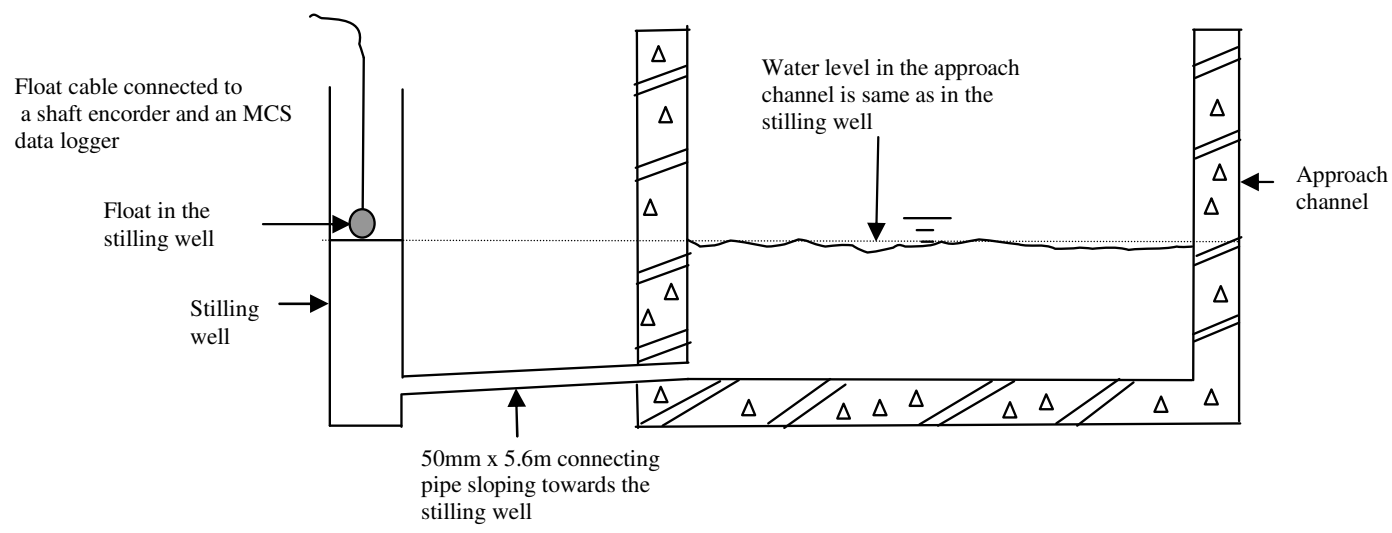

Fig. 7. A schematic diagram indicating the mechanism for monitoring the approach channel flow depth using a stilling well and float at the Potshini H-Flume. The length and width of the approach channel are $11.5 \mathrm{~m}$ and $2.7 \mathrm{~m}$ respectively.

analyzed from samples obtained from the $1.2 \mathrm{~km}^{2}$ catchment which was gauged by an $\mathrm{H}$-fume and equipped with an ISCO sampler, the latter being controlled by a data logger as illustrated in Fig. 7. The sampler had a capacity of 24 bottles of $500 \mathrm{ml}$ each and the sampling-trigger parameters in the data logger were varied, depending on the season, to achieve the desired sampling scheme. The local community had a significant role in this monitoring exercise where three members of the community, including the community facilitator, took turns to check on number of bottle samples already filled in the ISCO and notified the researchers by sending a cellphone text messages (SMS) when the number of remaining empty sample bottles in the ISCO was less than 10 .

The community facilitator was trained to remove samples from the ISCO, label the samples, replace the empty bottle cartridge in the right position and to reset the sampling scheme in the data logger. This had the benefit of ensuring that there were always empty sampling bottles in the ISCO, especially during the wet season if by any chance the researchers were not in the catchment. Manual samples for isotopic analysis $\left({ }^{18} \mathrm{O}\right.$ and $\left.{ }^{2} \mathrm{H}\right)$ were taken at the outlet of both the $1.2 \mathrm{~km}^{2}$ and $10 \mathrm{~km}^{2}$ catchments. These samples were mainly taken by the local community once every week (on a Monday) and labeled accordingly (i.e., site name and time of sampling). It should be noted that the main reasons for automating the measurement and sampling of stream flows were (i) for convenience purposes, especially during the night when it was difficult for both the researchers and community members to take samples and measurements and (ii) for continuous monitoring, thus accounting for extreme events e.g. big rainfall events which led to increased stream flows and sediment loads.

The water samples were temporarily stored in the instrumentation house of the H-Flume before being taken to the relevant laboratories for analysis. Some of these samples were displayed during field days in the community when other neighbouring communities (smallholder farmers) were invited. It was interesting for the smallholder farmers to note the clear difference between samples taken: (i) before a rainfall season (low flows); (ii) at the beginning of rainfall season; (iii) during a storm event; (iv) after a rainfall event and (v) the end of a rain season. Samples taken at the beginning of the rainfall season and during a storm event had more sediment material (dark brown in colour) compared to the rest. The samples taken during the low flows, dry winter season, were clear and void of sediments. From these visual observations, the smallholder farmers appreciated the fact that there was a relationship between the type of land cover on their farms, rainfall intensity and the sediment load, the latter being an indicator of loss of good fertile soil. This aspect was further reinforced through quantitative results which were graphically presented to the community during farmer's field days. The communication and feedback mechanism that was used in this study is highlighted in Sect. 4 of this paper.

\subsection{Climatic parameters}

Rainfall is clearly the main parameter that drives the hydrological cycle in a catchment, hence the need to observe its occurrence accurately, both spatially and temporally. Manual raingauges, if well managed, can provide relatively accurate daily rainfall data in a catchment and their affordability, availability and the ease of installation and operation makes them attractive, especially to smallholder farmers. After a reconnaissance survey in the catchment, several potential sites (homesteads) were identified in the Potshini community where manual raingauges were to be installed. The family members in these homesteads were then approached, beginning with the head of the homestead, to seek permission and the goodwill from the members of the homestead to permit the installation of the manual raingauges, and most importantly, to take daily rainfall readings at locations as shown in Figs. 1 and 3. A rainfall data recording booklet, translated into the local language - IsiZulu, was provided to 
the identified households and training to record and keep the daily rainfall records undertaken. The smallholder farmers recorded rainfall twice a day, i.e. at 09:00 $\mathrm{h}$ and 17:00 $\mathrm{h}$, from which the total daily rainfall was computed as the sum of the morning and evening readings. One of the profound statements made by one of the smallholder farmers who participated in monitoring rainfall in the catchment using a manual rain gauge was the fact that he was now in a position to tell, in quantifiable terms, how much it had rained and confidently share this information with his peers, unlike before he had a rain gauge.

One of the main factors that determine the planting date of the maize crop in Potshini, the main food source in the community, is the onset of rainfall. Farmers have been advised by the extension personnel in the district Department of Agriculture that they should sow their seeds after receiving a cumulative of $30 \mathrm{~mm}$ of rainfall. Thus, this underpins the importance which the most of the community members attach to monitoring of rainfall but which had previously been perceived as too difficult or complicated to undertake. The peer to peer learning and engagement process on rainfall monitoring in the Potshini community paid dividends when some of the other smallholders bought their own raingaguges and requested the SSI researchers to facilitate their installation and data recording. It was interesting to note the enthusiasm, in most community members, in participating in the monitoring of rainfall after the SSI researchers highlighted the fact that the daily television weather bulletin uses similar rainfall measurements to generate information on the distribution of rainfall in the country. Such an understanding increased the enthusiasm of the community members and engendered a feeling of importance of the monitoring exercise at both village and national level, and in fact raised hopes of hosting a national monitoring station in their midst.

The daily rainfall data was collected from the smallholder farmers by the SSI researchers on a weekly basis, during the rainfall season, and incorporated in a database for the Potshini catchment. Thus, voluntary participation of the local community in data collection promoted the philosophy of participatory catchment monitoring to the Potshini community as envisioned in the SSI research programme.

Rainfall data from the manual raingauges were augmented by climatic records from two automatic weather stations installed in the two nested Potshini catchment (cf. Fig. 1). One of the weather stations was installed in 2005 in the middle of the village (community weather station) and upstream of an existing telemetric weather station which was operational since 2002 on a nearby commercial farm and managed by the Agricultural Research Council (ARC) of South Africa. In 2007, a rainfall collector was attached to the automatic raingauge in the community weather station to collect rainwater for analysis of isotopic composition of ${ }^{18} \mathrm{O}$ and ${ }^{2} \mathrm{H}$. The collector comprised six- $400 \mathrm{ml}$ bottles which filled sequentially during a rainfall event and is designed to prevent evaporation of the collected samples. The community members assisted

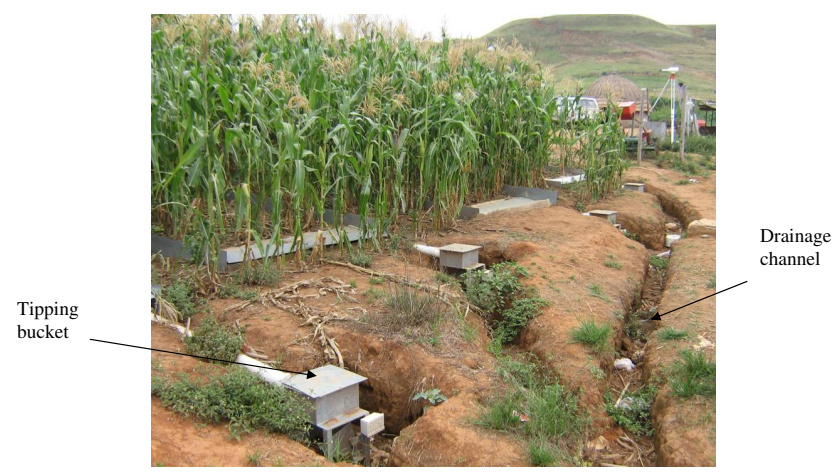

Fig. 8. A set of runoff plots under different treatments in a farmermanaged trial.

in storing and labeling of the rainwater samples after a rainfall event and emptied the bottles to allow fresh rainwater samples to fill the bottles during a subsequent rainfall event. Since its installation, the weather station in the middle of the village was maintained by the local Potshini community, including fencing of the station and maintaining tidiness within and on the surrounding area. Fencing of the weather station was necessary to safeguard the instrumentation against the cattle which grazed freely, especially during the dry winter season. Otherwise the security of the weather station was entrusted to the local community, through the traditional leadership of the community and the goodwill generated by the participatory engagement of the Potshini community and other stakeholders at the initial stages. The climatic data from these two stations was accessible to researchers in the ARC, the SSI programme and any other interested stakeholder.

\subsection{Runoff plots}

One of the research themes in the SSI research programme was aimed at investigating the hydrological processes and determine water balance in smallholder farmers' fields ( $<1$ ha) and hence runoff plots were installed for this purpose; as controlled micro-catchments. Seventeen runoff plots, with similar slopes and under different treatments, i.e. conservation and conventional tillage practices were installed at three different smallholder farms and one researcher-managed trial. The latter was a controlled site where experimental set up and trials, with some of the treatments being similar to the farmer- managed trials, were carried out in an effort to compare and validate the results from the farmer managed trials (Kosgei, 2009). Figure 8 shows a set of runoff plots at a farmer managed trial site.

\subsubsection{Surface runoff}

Various measurements were carried out in the runoff plots including monitoring the surface runoff, sediment load, volumetric soil moisture content, soil hydraulic characteristics, 
crop transpiration rates, crop phenological properties and biomass production. Three members of the Potshini community were trained and participated in the installation of the runoff plots, including the automation system in monitoring some of the processes e.g. surface runoff, sediment load, soil moisture, etc. These members of the community appreciated the convenience of automating the data recording process and took interest in understanding the principles applied. Payment for services was not the norm, but in most cases, when working in the field, the SSI researchers either organized packed lunch for all i.e. the members of community working with them and themselves, or arranged for food to be prepared for all in a homestead of one of the community members. Such an approach further perpetuated a sense of togetherness and cohesion between the community and researchers.

The tipping buckets (cf. Fig. 9), in all the runoff plots had both manual counters, for counting the number of tips on each bucket, and an electronic recording system with a proxy switch connected to a data logger. The manual counters were very useful when explaining the impact of the different tillage treatments on runoff generating characteristics to farmers during field days. The farmers could clearly see from the manual counters the comparative difference in the number of tips in the runoff plots under conservation and conventional tillage systems, of which the latter had more tips (Kosgei, 2009). Thus, the community appreciated the fact that more water is conserved under conservation tillage practices compared to conventional tillage practices.

\subsubsection{Sediment load}

Sediment loads were recorded from the different treatments, using a sediment sampler, in the five treatments at the research managed trial site. The sediment samplers consisted of flow splitting containers (flow splitters) and a sample storage tank. The flow splitters, Fig. 9, captured the discharge from one side of a tipping bucket (half of the total flow from a runoff plot) during each runoff event.

After each runoff event, and after vigorous stirring, $500 \mathrm{ml}$ discharge samples were manually taken from the sample tank and labeled by members of the local community for sediment load analysis and composition of stable isotopes of water. The sample tanks were emptied by the members of the community after the sampling exercise to allow fresh discharge to drain into the tanks in subsequent runoff events. The smallholder farmers were also shown, during field days, some of the samples taken from each treatment after rainfall events and it was clear that samples obtained from runoff plots under conventional tillage systems had more sediment compared to those from conservation tillage.

The smallholder farmers appreciated the results obtained from the runoff plots experiment, including the potential to conserve soil moisture and soil nutrients when using conservation tillage system. Some of the results obtained from

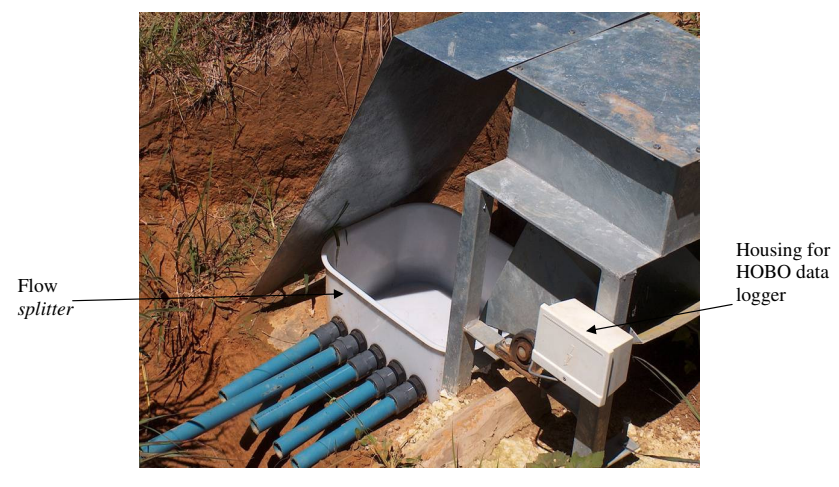

Fig. 9. A tipping bucket with flow splitter.

this experimental set-up are highlighted in Kongo and Jewitt (2006) and Kosgei et al. (2007). However, the smallholder farmers noted two main challenges, i.e. the cost implication of implementing conservation tillage compared to the conventional system and the inability to keep sufficient crop residues on their farms (mulching) due to uncontrolled grazing of livestock in the community during the dry winter season.

Despite these challenges, the farmers noted and appreciated the potential benefits of conservation tillage systems in ensuring their food security and took a proactive stance in procuring a community No-Till planter. In early 2010, the Potshini community leadership approached the SSI researchers and requested the University of KwaZulu-Natal, through the School of Bioresources Engineering and Environmental Hydrology (SBEEH), to assist them in purchasing the planter. The school of BEEH and the Potshini community agreed to share equally the cost of purchasing the planter (cf. Fig. 10), the total of which was R12 000 (currently approximated at US\$1720). Such a proactive endeavour by the smallholder farmers, in investing resources as a result of lessons learnt from the conservation tillage experiments, is evidence of the contribution of research to improving livelihoods of the local people in the Potshini community.

It was interesting to note that two of the three members of the community who participated in installing the runoff plots under the SSI research programme were hired a year later by another research project in the same area to install runoff plots for monitoring runoff and sediment load under different engineered slopes e.g. roads embankments etc. The training further gave these community members an insight into the systematic process of setting a field experiment including the rigour required in ensuring good representative samples and measurements.

\subsubsection{Soil moisture profiling}

A weekly monitoring exercise for volumetric soil moisture content in the Potshini catchment was established in 2005. Readings were taken at $30 \mathrm{~cm}$ intervals along the soil profile 


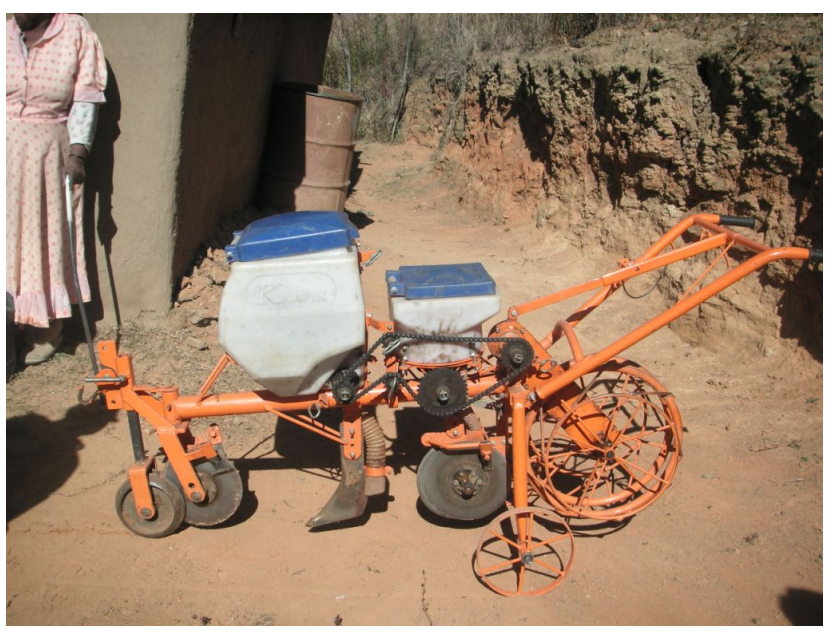

Fig. 10. The Potshini community No-Till planter.

in all runoff plots. The installation of access tubes, for guiding the Time Domain Reflectometry (TDR) probe along the soil profile, were installed with the participation of the local community, who also took soil moisture reading on a weekly basis. Notably, each owner of the smallholder farms where the runoff plots were installed took part in the installation process and also in taking the measurements at their own site through a process formulated by the community facilitator. The facilitator was the custodian of the TDR probe and most often, during community meetings, field days and peer farmer's visits, he showed his fellow community members the process of taking soil moisture readings. The community members were able to appreciate the fact that it was possible to quantify soil moisture and the effect of different tillage systems on soil moisture. The weekly soil moisture data obtained from all runoff plots indicated that conservation tillage conserved more soil moisture, especially during the dry season, compared to conventional tillage practices. This was clearly evident in plots that had sufficient mulch and crop residues. The soil moisture results obtained from these experimental plots, and graphically presented to the community, motivated other smallholder farmers to use mulching in their kitchen gardens during the dry winter season. The gardens were promoted by the SSI researchers in the Potshini catchment as one of the strategies to improve livelihoods in the community where the smallholder farmers were introduced to rainwater harvesting techniques to store rainwater for irrigating kitchen gardens during the dry winter season (Kosgei, 2009). The weekly soil moisture data on these experimental plots was complemented with data from Watermark sensors (Allen et al., 2000; Hanson and May, 2006), where a nest of three sensors were installed in all the 17 runoff plots in the catchment at depths of 30,60 and $90 \mathrm{~cm}$. The data sets from the Watermark sensors were presented to the community members, during farmer's days, and through this instrumentation set-up the smallholder farmers appreciated the fact that soil water takes time to percolate and move down the soil profile and that percolation is a function of soil type and surface cover.

\subsection{Monitoring of shallow ground water}

Subsurface flows constitute an important component in developing a water balance for a catchment and hence the need to monitor their occurrence and magnitude. The shallow ground water in the Potshini catchment was monitored via 12 shallow ground water wells (piezometers), which were installed through the collaboration and participation of the local community. Figure 3 shows the layout of the shallow groundwater wells in the catchment. Since the intensivelymonitored upper sub-catchment (cf. Fig. 1 and 3) is predominantly an agricultural area for smallholder farmers, permission was sought from the local leaders and individual farmers to allow the augering of the $100 \mathrm{~mm}$ diameter holes in some of the farms before inserting special $63 \mathrm{~mm}$ diameter pipes. The wells were located along transects, and strategically installed on sites where they could not interfere with the farming activities, since most of the farming operations in the area make use of animal and or tractor drawn implements. Pressure transducers were then installed in 8 of the shallow ground water wells and $\mathrm{HOBO}$ data loggers recorded the fluctuation of the water table at a time step of $30 \mathrm{~min}$. The installation of the 12 shallow groundwater wells, like any other installation in the community, was preceded by a meeting with the community where the SSI researchers explained the objective and approach of the experimental setup. It was interesting to note that some community members had previously thought that the wells could be used for irrigating their farms, a point which was clarified during the meeting. Some of the community members were interested to know how deep the groundwater was in their farms and possibly its quality and hence they enquired about the possibility of extending the installation of the wells to their own farms. Thus, the farmers were not compensated for installing these wells in their farms but rather were all looking forward to having the wells in their midst. Labour was sought from the community in augering these wells and paid at the standard national rate at the time of R75 per day (about US\$ 10 in 2005). However, as highlighted in Sect. 3.71, this payment was considered more of an appreciation of their time and not exchange for labour as it is in most cases.

The shallow groundwater table in the Potshini catchment was observed to respond faster to rainfall events, occasionally rising to less than $1 \mathrm{~m}$ below ground surface after high intensity rainfall events, and receding to below the piezometer depths (below $3 \mathrm{~m}$ ) during the dry winter season. This information was shared and presented to the community, during community meetings, field days, etc., and it was apparent that most of the community members had not anticipated the seasonal fluctuations of shallow groundwater of this magnitude in the area. The community members managed to link 
these observations with the filling of their pit latrines with subsurface water during the wet season, especially those in the low lying areas, and failure of foundation in some houses in the community. The community members also mentioned the fact that some of the crop failure in the community was attributed to water logging during the peak of the rainfall season. The SSI researchers highlighted the fact that there was a potential danger of polluting the shallow groundwater resource in the community through the direct contact and mixing of the waste in pit latrines and the shallow ground water. This cautious remark was supported by the fact that the soils in the catchment had a relatively high hydraulic conductivity (Kongo, 2008). These results and observations were beneficial to the community as some members started using concrete blocks to build their pit latrines and also reinforcing the foundation of their houses.

\subsection{Monitoring of deep groundwater}

Through funding from the KwaZulu-Natal Provincial Department of Water Affairs and Forestry ${ }^{3}$ (DWAF), and in collaboration with the local community, two deep ground water observation well sites were identified and the boreholes subsequently sunk in the Potshini catchment. It should be noted that the main source of domestic water in the community is groundwater. However, there was uneven distribution of water supply wells in the catchment, especially towards the southern part. Thus, the community requested that one of the boreholes to be used for supplying domestic water especially in the area with no water supply wells. It was then agreed, between the SSI researchers, DWAF and the Potshini community that one of the boreholes was to be dedicated to monitoring of deep groundwater table and the researchers were to decide where to install it in the catchment, after conducting geophysical measurements, while the community was to decide where to install the second borehole. The borehole log information of the $120 \mathrm{~m}$ deep well that was installed solely for research purposes is as shown in Fig. 11.

The community was happy with this arrangement and further gave the researchers' permission to monitor the groundwater levels in the new community borehole as well as three other boreholes, previously installed by the local authorities, which were being used by the community for water supply. Thus, through the participatory engagement, the researchers were able to expand the spatial coverage of monitoring deep ground water in the catchment including monitoring for the stable isotopes. However, it was apparent that the community would still have agreed to the researcher's request even if there were limited funds to sink only one observation well for research purposes, thus highlighting the good working relationship that had been established between the researchers and the community at that time. DWA continue to support the monitoring of the deep groundwater in the Potshini

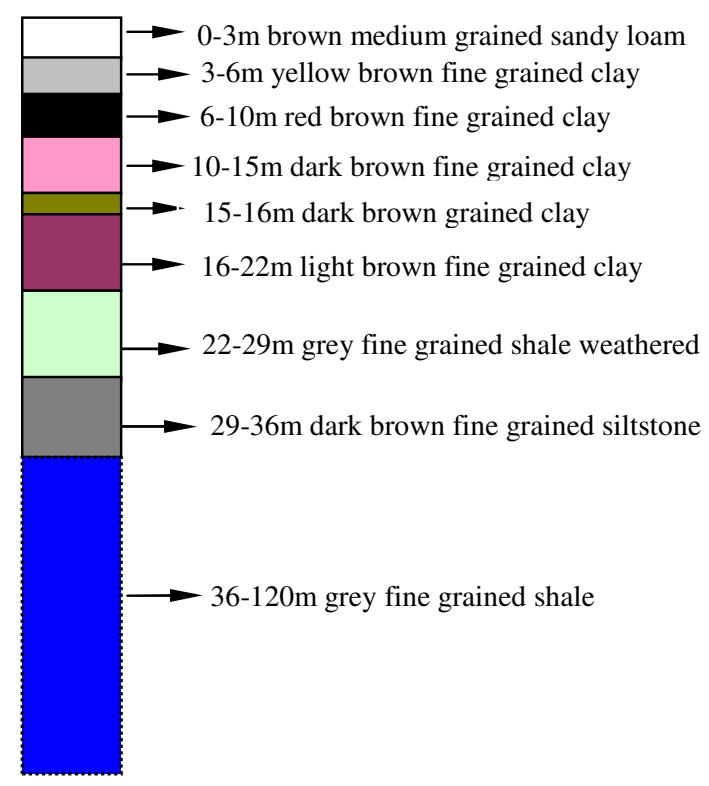

Fig. 11. Borehole log information including the lithology, grain size and colour for a $120 \mathrm{~m}$ deep observation ground water well in the Potshini catchment.

catchment, even after the end of the SSI research programme, as part of an initiative to monitor ground water in the larger Thukela river basin and hence meeting the community's desire for a nationally relevant monitoring site to be established in their midst.

\subsection{Electrical Resistivity Tomography (ERT) survey}

The geophysical Electrical Resistivity Tomography (ERT) techniques are non-destructive techniques that provide a pseudo-section of apparent or effective resistivity of the subsurface. These pseudo-sections are then inverted to provide an interpretation of the actual resistivity distribution in a 2D section of the subsurface. More literature on the description, theory and practical application of ERT is highlighted in Loke (2003). The 2-D Electrical Resitivity Tomography (ERT) surveys in the Potshini catchment were carried out with the objective of characterizing the occurrence of subsurface water. Thus, the mapping was aimed at augmenting and up-scaling the monitoring of the point-shallow ground water in the catchment, using shallow ground water wells, to a relatively larger spatial extents and depths. The survey were repeatedly carried out along the same transects over time, during the wet and dry season, in collaboration with the local community, where acceptance was sought from the local leaders and individual owners of the parcels of land where the survey transects were to pass through. Figure 12 shows a layout of the ERT survey transects in the Potshini community.

\footnotetext{
${ }^{3}$ Now Department of Water Affairs
} 


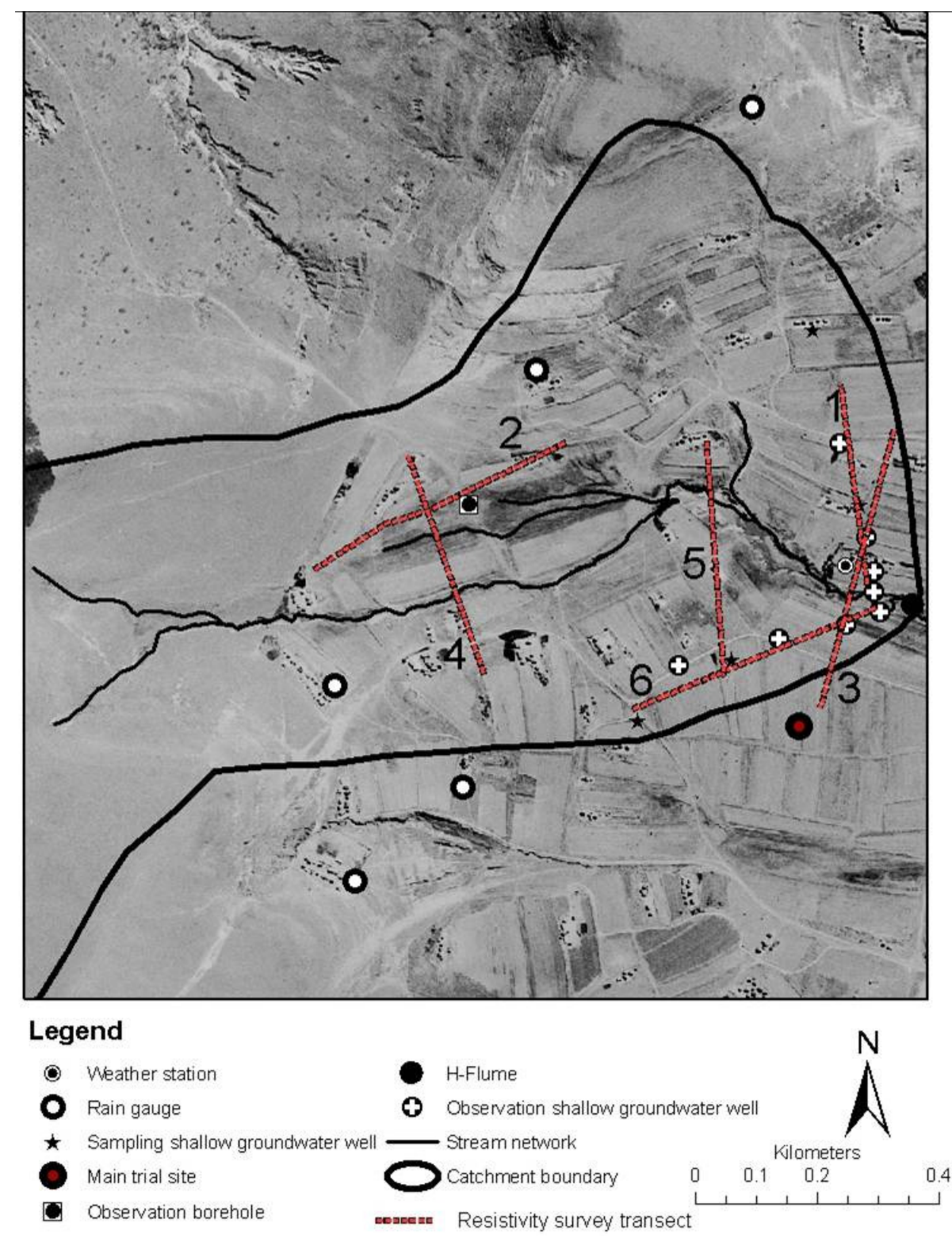

Fig. 12. Location of resistivity survey transects in the Potshini catchment.

Five members of the community were engaged and paid the standard daily wages in the mapping exercise. It was interesting to note the curiosity that this exercise generated in the community. Occasionally, a group of anxious members of the community would join the mapping team for an explanation on the measurement procedures and data interpretation. This prompted the SSI researchers to arrange for a demonstration exercise to the community where all the details on the protocol, measurements and validation of the resistivity data were highlighted. The community members understood the concept of ERT mapping on the explanation that it was synonymous to a medical X-ray examination, with which they were familiar. Thus, they appreciated the fact that it is possible to have an idea of how the "bowels" of the earth looks like, including occurrence of groundwater, without excavation. Some of the community members even requested for ERT mapping to be done in their homesteads to determine suitable sites, with low water tables, for digging pit latrines. In this regard, the community members, again, realized a direct benefit of having the mapping exercise being done close or across their farms and homesteads and hence they encouraged the SSI researchers to expand the mapping to cover as much area as possible in the community. However, due to time and equipment availability constrains only six transects (cf. Fig. 12) were identified and repeatedly mapped over different seasons. 


\subsection{Monitoring of total evaporation using a Large Aperture Scintillometer}

The conventional approaches for quantifying total evaporation (ET) have been based on localized point measurements and hence constrain the estimation of the flux over large geographical areas. A Large Aperture Scintillometer (LAS) is an instrument that measures sensible heat flux, a component of the surface energy balance, over a transect (typically less than $10 \mathrm{~km}$ ). With known net radiation (obtained from net radiometers in weather stations) and soil heat flux (obtained from field soil heat flux measurements), the latent heat flux can be computed as a residual in the energy balance equation as indicated in Eq. (1).

$\lambda E_{t}=R_{\mathrm{n}}-H-G$

where $\lambda E_{t}$ is the latent heat flux $\left(\mathrm{W} \mathrm{m}^{-2}\right), R_{\mathrm{n}}$ is the net radiation $\left(\mathrm{W} \mathrm{m}^{-2}\right), H$ is the sensible heat flux $\left(\mathrm{W} \mathrm{m}^{-2}\right)$ and $G$ is the soil heat flux $\left(\mathrm{W} \mathrm{m}^{-2}\right)$. The total evaporation can then be computed from the latent heat flux.

The measurement of total evaporation in the Potshini catchment using LAS at the Potshini catchment, Fig. 13, started in April 2006 and continued until early 2007, though the exercise was occasionally interrupted after the LAS was damaged by local lightning strikes, especially during the wet summer season, and it took some time to get the instrument repaired due to technical and logistical problems. The frequency of measurement with the LAS was every minute and the instrument was left in the field throughout the measurement period. The installation and siting of the LAS was done in collaboration with the local community in the Potshini catchment. The community members were amazed when they were informed of the cost of purchasing the LAS, which in 2004 was around US\$ 60000 , and appreciated the trust the SSI programme had in them by installing such expensive equipment in their midst. By 2004, there were less than 5 Large Aperture Scintillometers in Africa and one of them was running in the rural Potshini community in South Africa. Thus, the LAS became a status symbol for the community. This was evident when the community leadership suggested, during installation, that the receiver and transmitter to be installed in homesteads of good reputation for safety purposes. This suggestion was adhered to by the SSI researchers and the goodwill of the whole community was sought with regard to the safety and security of this state of the art instrument.

Consequently, the transmitter and the receiver were stationed at homesteads in the community, and the owners volunteered to maintain and ensure the security of this expensive instrumentation. The whole community was involved during the initial stages of installing the LAS through community meetings which were mobilised by the local leadership. The transmitter was powered by mains power supply, from one of the homesteads, and the the SSI research programme paid for both its power consumption and that of the homestead as a form of appreciation for the commitment by the head of the

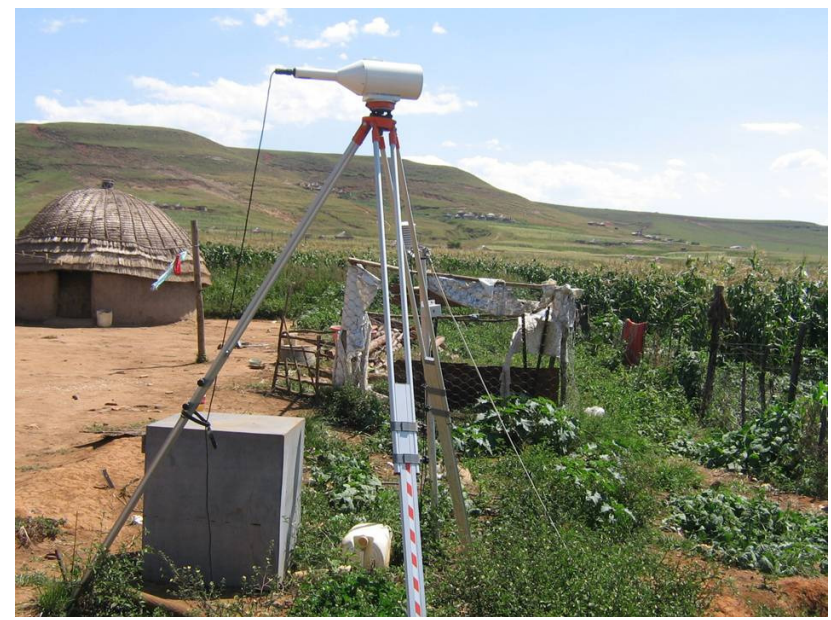

Fig. 13. The receiver of the Large Aperture Scintillometer in one of the homesteads in the Potshini catchment.

homestead to safeguard the equipment in his homestead. The LAS was an attraction to many visitors in the community, including Government department officials.

The SSI researchers had to furnish the community facilitator with sufficient information on the LAS to enable him respond effectively to questions from visitors. The facilitator also used such inquisitive visits to the LAS to inform the visitors of the other SSI research initiatives and instrumentation in the catchment and hence it provided a platform for communication and outreach. The data sets obtained from the LAS were presented to the community members together with the remote sensing estimates of total evaporation as highlighted in Sect. 3.12.

\subsection{Remote sensing}

There are many applications of remote sensing in water resources management including hydrogeologic mapping, landuse change studies, estimation of total evaporation, mapping and monitoring of wetlands etc. One of the main application of remote sensing in the Potshini catchment was the estimation of total evaporation (ET) in the catchment and a larger part of the Thukela river basin using the Surface Energy Balance Algorithm for Land (SEBAL), (Bastiaanssen et al., 1998a,b; Bastiaanssen, 2000). Some results on the validation of SEBAL, using data from the LAS, in the Potshini catchment is highlighted in Kongo et al. (2010).

The local community were unable to comprehend the SEBAL's theory but understood the concept of the surface energy balance. Some community members understood the link between the LAS measurements and the remote sensing studies that were applied on a larger scale. SEBAL results (ET maps) covering the Potshini catchment and surrounding areas were presented to the community members, during a feed-back session, and it was interesting to note how 
the smallholder farmers comprehended the results in the context of their land uses. The smallholder farmers managed to identify and highlight from the map that there was less ET over the grazing areas compared to cultivated areas. They attributed this to lack of good vegetative cover of which is important in protecting the soil from erosive forces.

\section{Communication and feedback platforms for learning and sustainable adoption}

In the SSI programme, some of the participatory techniques used included case studies, informal discussions, work sharing, village presentations, field days, process notes, personal diaries, semi-structured interviews, key informants and matrix scoring (Sturdy et al., 2008). An effective participatory learning process must involve a feedback mechanism where continuous updating and response are integrated in the learning process. Such feedback mechanisms should accommodate as much as possible, the opinions and ideas from the various stakeholders. In the Potshini catchment, feedback forums were promoted and encouraged for all stakeholders, at the various levels of participation, where the respective stakeholders were continuously updated on the main research findings, progress on data collection and upcoming research activities within a year. It is during such feedback sessions that the respective stakeholders obtained an in-depth understanding of the ongoing research activities, and appreciation of their contribution to the SSI research programme and to understand the vagaries of hydrological processes in their catchment. As highlighted by (Liniger and Critchley, 2007), dissemination of information is a socio-cultural process and a critical component of developing sustainable change in a community and the spontaneous spread of innovations occurs almost exclusively through farmer-to-farmer information exchange.

A monthly Farmers Forum, established as a communication and management platform for farmers in the Emmaus ward (the administrative ward in which Potshini falls) in the Bergville District under the then Agricultural Research Council's (ARC) Landcare Project, proved to be a useful platform for the researchers, for dialogue with farmers and for other stakeholders in the area. This forum provided an entry point for the SSI team and through it, the researchers were able to outline the objectives of the SSI programme in the area, its implementation and most importantly the usefulness of voluntary participation of farmers in the research programme. The researchers managed to effectively use the farmer-to-farmer learning structures previously put in place by the ARC Landcare project (Smith et al., 2004) for establishing contact with individual smallholder farmers who were willing to participate in the SSI research programme, especially in the catchment monitoring exercise. It is through such forums that a good working relationship between the local statutory organizations (both Provincial and District offices) and the research team were established. Since then, the SSI Programme continued to benefit and enjoyed the support of these organizations and the SSI researchers attended or were represented at relevant provincial and municipal level functions, which provided a forum for all stakeholders and development projects working in the District on food security, home economics, community resources and the agricultural sector. The SSI research team participated in all nearby field days organized by these bodies in Potshini and other nearby wards in the Bergville District and likewise, these bodies actively participated, and even facilitated some of the field days organized by the SSI research programe in Potshini.

\section{Key lessons from the participatory catchment monitoring in Potshini}

Engaging stakeholders is a process, with varying challenges depending on who is engaged and the basis for engagement. Most of rural communities in sub-Saharan Africa are engaged in either agricultural or pastoral activities and often support or adopt initiatives that are geared towards enhancing their livelihoods. These communities have governance structures, formal or informal, of which the leadership and the community at large expect to be recognized and respected by all including visitors. This was the case in the Potshini community. From our perspective, the SSI programme managed to achieve more in the various projects that were implemented in the Potshini catchment, including the participatory catchment monitoring, through the recognition and appreciation of the governance structures in the community and working within these structures. A similar approach was used when engaging the various government departments in Bergville district and the KwaZulu-Natal Province. Thus, there is always a process to follow (informal and or informal) when engaging stakeholders, which needs to be based on trust, honesty and friendship.

It is recognized that there are always key individuals, with influence, in any institutional set up. Some of these individuals may be of reputable character in the community, innovative and or outspoken in nature etc. These individuals form a network of respected persons in the community whose advice is most often respected by all. It is recognized that many community members would not risk to venture into new ideas unless they see the ideas working or succeeding for others. Thus, one can expect rapid diffusion of an idea to the community if the respected persons take up the new idea and implement it with success. The community leaders in the Potshini community played a key role in the catchment monitoring after they took the lead in implementing some of the monitoring activities e.g. monitoring rainfall, farmer managed tillage trials etc. It is useful to note that the good yield 
results from the various tillage trails in the Potshini catchment, including the farmer-managed trials, gave the Potshini community the confidence to invest their resources to buy a No-Till planter, with the help of the University of KwaZuluNatal as discussed in Sect. 3.72.

Engaging the learning institutions in the local area has both immediate and long term benefits as was realized in the Potshini community. The Potshini secondary school was engaged in the monitoring process where the final year students were always given a practical overview of the various experimental set ups and the larger integrated monitoring network. This was implemented through the school curriculum's Life Science subject. Such an approach created a learning mechanism in the community and had a much wider impact, reaching many more people in the community than previously thought.

In most social or development processes, the ultimate benefits to the community are not necessarily known. However, the process creates a platform for other opportunities. This is normally the case where various development partners and stakeholders are actively engaging with the local community. The initiation of rainwater harvesting and storage in the Potshini catchment was received positively by the local community and other development stakeholders including government departments. This was evident after the three farmers (homesteads), who had been facilitated by the SSI programme to harvest and store rainwater for supplemental irrigation for their kitchen gardens, managed to improve their livelihoods through sale of vegetables during the dry winter season. This success story precipitated the commissioning of a community development project in Potshini by the Water Research Commission (WRC) of South Africa. The WRC project provided $20000 \mathrm{~L}$ water storage tanks to 40 homesteads in Potshini for storing rainwater for supplemental irrigation in their kitchen gardens and there were plans to outscale the WRC project to other nearby communities. Thus, starting a useful and beneficial process brings or attracts other unexpected and or indirect benefits. However, the challenge is to be able to identify whether a process is useful, beneficial and relevant to the target community.

Generally, researchers are expected to own their respective processes including information emanating from their findings. However, undertaking a research initiative in a rural community brings a fairly amount of responsibility to the researchers given the lack of capacity in these communities to counter check research findings in their midst. This is critical when the research findings are communicated to the rural community at or during decision making forums as was the case with the SSI programme. This is an ethical issue in science that needs to be given more attention in this context, while at the same time communicating effectively on both complex and simple issues without raising false hopes or raising unnecessary alarms to the community. In most cases, the rural community will always attribute any development in their midst to the person (e.g. researcher, engineer etc.) who brought the idea. Thus, in a rural community setting, it is the responsibility of the respective researchers to own to their processes and respective findings.

One question that one could ask is whether the SSI researchers had an alternative to the time consuming but useful process of engaging the local community and other stakeholders in establishing the catchment monitoring network and implementing the SSI programme at large. The answer to this question is a big "YES". One of the obvious approaches could have been paying people for their services e.g. taking rainfall readings, guarding all the installations in the catchment etc. However, this process is not sustainable as has been proven in other research catchments in the region. Sustainability requires endurance of purpose while having a long-term objective as was the case in establishing the Potshini catchment monitoring network. The engaging with the local community and other stakeholders did not necessarily change too much on the design of the network but rather provided an opportunity for ownership, learning and appreciation, to the researchers, local community and other stakeholders. There are cases in the region where catchment monitoring networks have been regarded as a "threat" by rural communities and hence vandalized. Unfortunately, the missing link in such cases is information sharing (between researchers and local communities) and appreciation of other people's diversity, strengths and weaknesses.

Most research institutions engaged in biophysical research tend to pay less attention to the soft side of their "hard-core" scientific disciplines. This ideology and tendency could be true for institutions heavily committed to socio-economic research. The School of Bioresources Engineering and Environmental Hydrology (SBEEH), University of KwaZuluNatal, has been conducting research on process hydrology for a long time while establishing research catchments in various parts in the southern Africa region. These research catchments were established in areas owned by cooperate institutions e.g. forest companies, etc and not by rural communities as was the case with the Potshini catchment. One of the profound lessons by SBEEH was the appreciating the challenges of establishing a research catchment in the midst of a community. Such an appreciation led to a paradigm shift on how to deal with such challenges. For example, the SBEEH is now prepared and willing to commit funds to "soft" (social) issues related to maintaining the integrity of the Potshini catchment and will take due recognition of lessons learned from the Potshini catchment when establishing similar research catchments in future. Thus, the lessons learnt in establishing of the Potshini catchment monitoring network have brought about an institutional alignment and appreciation of non-traditional challenges which could otherwise be neglected. 


\section{Conclusions}

Catchment monitoring is fundamental to understanding the various hydrological processes in a catchment. Using this understanding, researchers formulate catchment responses which aid in water resources management. This paper highlighted and underscored the importance of applying Participatory Research techniques in hydrological research studies where other stakeholders are involved. The feedback process where various stakeholders were updated on the research activities including visual interpretation of the data collected from the catchment monitoring network proved to be a useful tool in instilling a sense of ownership to the local community while the other stakeholders appreciated their contribution and participation in the SSI research programme, thus enhancing sustainability of the catchment monitoring initiative in the community.

The experience drawn from establishing the catchment monitoring network in Potshini, a rural community in Bergville District in South Africa, has proved that there are more opportunities and gains (both material and ideas) to benefit from involving other stakeholders. In particular, the establishment of the goodwill of the local community in Potshini avoided, to a large extent, problems of vandalism or theft that have plagued several research catchments in South Africa and other parts of the world. The level and stage of participation of each stakeholder differs but ultimately contributes to the success of such a process. The Potshini catchment monitoring network had several permanent structures and instrumentation which continue to benefit researchers. The structures and instruments were installed in individual farms belonging to willing smallholder farmers in the Potshini community. A number of the farmers volunteered to monitor some of the hydrological processes and take readings accordingly. The traditional leadership in Potshini agreed to host and support the SSI research programme and the local elected leaders facilitated, to a great extent, the linking of the SSI researchers to the local municipality officials while the extension personnel from the Agricultural statutory bodies and the ARC-Landcare project in Bergville played a key role in linking the SSI research programme with other similar projects and stakeholders in the Bergville district and beyond.

Additional data collection by community members can be of significant value in building an understanding of the biophysical system by the community members involved. This does limit the control a researcher may have over the experiment, leading to a need for careful cross-referencing and quality control of data. However, this is outweighed by the immediate benefit of aligning the project with the socioeconomic as well as biophysical conditions present within the community involved (Sturdy et al., 2008). The result is an experiment that community members understand and can explain to others, and that is suitable for local conditions. Thus, the participation of a local community in a hydrological monitoring programme need not compromise the quality of the scientific endeavour nor the level of sophistication of the instrumentation used. The participatory process of establishing the Potshini catchment monitoring network emerged as a positive impact on the local community and other stakeholders with regard to appreciating the research findings and above all, the ability to sustain the goodwill of the local community in safeguarding the instruments and structures comprising the network.

Acknowledgements. The work reported here was undertaken as part of the Smallholder System Innovations in Integrated Watershed Management (SSI) Programme funded by the Netherlands Foundation for the Advancement of Tropical Research (WOTRO), the Swedish International Development Cooperation Agency (SIDA), the Netherlands Directorate-General of Development Cooperation (DGIS), the International Water Management Institute (IWMI) and UNESCO-IHE Institute for Water Education and Stockholm University (SU). The authors are grateful to the Stockholm Environment Institute (SEI) for granting the lead author a research grant, through the Research Capacity Fund, towards accomplishing this paper. The authors are also grateful for the goodwill and support from the Potshini community, the District Department of Agriculture and Environment office in Bergville, Department of Water Affairs and Forestry in KwaZulu-Natal Province, the Okhalhamba Municipality and the Agricultural Research Council of South Africa. Lastly, we are grateful to Stacey Noel of SEI-Africa Centre for proof-reading this manuscript.

Edited by: M. Sivapalan

\section{References}

Ackers, P., White, W. R., Perkins, J. A., and Harrison, A. J. M.: Weirs and flumes for flow Measurement, Wiley Interscience Publication, USA, ISBN No 047199637 8, 1978.

Andreas, E. L.: Two-wavelength method of measuring pathaveraged turbulent surface heat fluxes, J. Atmos.c Ocean Tech., 6, 280-292, 1989.

Bastiaanssen, W. G. M.: SEBAL-Based Sensible and latent heat fluxes in the irrigated Gediz Basin, Turkey, J. Hydrol., 229, 87100, 2000.

Bastiaanssen, W. G. M., Menenti, M., Feddes, R. A., and Holtslag, A. A. M.: A remote sensing Surface Energy Balance Algorithm for Land (SEBAL), Part 1: Formulation, J. Hydrol., 212-213, 198-212, 1998a.

Bastiaanssen, W. G. M., Pelgrum, H., Wang, J., Ma, Y., Moreno, J., Roerink, G. J., and van der Wal, T.: The Surface Energy Balance Algorithm for Land (SEBAL), Part 2: Validation, J. Hydrol., 212-213, 213-229, 1998b.

Bhatt, Y., Bossio, D., Enfors, E., Gordon, L., Kongo, V. M., Kosgei, J. R., Makurira, H., Masuki, K., Mul, M., Tumbo, and S. D.: Smallholder System Innovations in Integrated Watershed Management (SSI): Strategies of water for food and environmental security in drought-prone tropical and sub-tropical agroecosystems, IWMI Working Paper 109, SSI Working paper 1, International Water Management Institute, Colombo, Sri Lanka, 59 pp., 2006. 
Cain, J. D., Rosier, P. T. W., Meijninger, W., and De Bruin, H. A. R.: Spatially averaged sensible heat fluxes measured over barley, Agr. Forest Meteorol., 107, 307-322, 2001.

Chow, T. V., Maidment, D. R., and Mays, L. W.: Applied hydrology, McGraw-Hill, 1988.

Farah, H. O. and Bastiaanssen, W. M. G.: Impact of spatial variation of land surface parameters on a regional evaporation: a case study with remote sensing data, Hydrol. Process., 15(9), 15851607,2001

Gilvear, D. J. and Bradley, C.: Hydrological monitoring and surveillance for wetland and management-a UK perspective, Phys. Chem. Earth, 25, 571-588, 2000.

Hill, R. J.: Review of optical scintillation methods of measuring the refractive index spectrum, inner scale and surface fluxes, Wave. Random Media, 2, 179-201, 1992.

Hodgson, G. A., Bartle, G. A., Silberstein, R. P., Hatton, T. J., and Ward, B. H.: Measuring and monitoring the effects of agroforestry and drainage in the "Ucarro" sub-catchment, Agr. Water Manage., 53, 39-56, 2002.

Ireson, A. M., Wheater, H. S., Butler, A. P., Mathias, S. A., Finch, J., and Cooper, J. D.: Hydrological processes in the Chalk unsaturated zone-insights from an intensive field monitoring programme, J. Hydrol., 330, 29-43, 2006.

Kite, G. W. and Droogers, P.: Comparing evapotranspiration estimates from satellites, hydrological models and field data, J. Hydrol., 229, 3-18, 2000.

Kohsiek, W. and Herben, M. H. A. J.: Evaporation derived from optical and radio wave scintillation, Appl. Optics, 22, 2566-2569, 1983.

Kongo, M. V.: Balancing water for food and environment: hydrological determinants across scales in the Thukela river basin, South Africa, PhD thesis, School of Bioresources Engineering and Environmental Hydrology, University of KwaZulu-Natal, 2008.

Kongo, M. V. and Jewitt, G. P.W .: Preliminary investigation of catchment hydrology in response to agricultural water use innovations: a case study of the Potshini catchment-S. Africa, Phys. Chem. Earth, 31, 976-987, 2006.

Kongo, M. V., Jewitt, G. P. W., and Lorentz, S.A. Establishing a catchment monitoring network through a participatory approach: A case study from the Potshini catchment in the Thukela river basin, South Africa, International Water Management Institute, Colombo, Sri Lanka, P66, IWMI Working Paper 120, 2007.

Kongo, M. V., Jewitt, G. W. P., and Lorentz, S. A.: Evaporative water use of different land uses in the upper-Thukela river basin assessed from satellite imagery, Agr. Water Manage., in press, 3057, doi:10.1016/j.agwat.2010.06.005, 2010.

Kosgei, J. R.: Rainwater harvesting systems and their influences on field scale soil hydraulic properties, water fluxes and crop production, $\mathrm{PhD}$ thesis, School of Bioresources and Environmental Hydrology, University of KwaZulu-Natal, 2009.
Kosgei, J. R., Jewitt, G. P. W., Kongo, V. M., and Lorentz, S. A.: The influence of tillage on field scale water fluxes and maize yields in semi-arid environments: A case study of Potshini catchment, South Africa, Phys. Chem. Earth, 32(15-18), 1117-1126, 2007.

Loke, M. H.: Electrical imaging surveys for environmental and engineering studies: A practical guide to 2-D and 3-D surveys, available online at www.abem.com, last access: June 2008, 63 pp., 2003.

Lorato, N., Love, D., and Hoko, V.: Involvement of stakeholders in water quality monitoring and surveillance system: the case of Mzingwane catchment, Zimbwabwe, Phys. Chem. Earth, 31, 707-712, 2006.

Marschke, M. and Sinclair, J. A.: Learning for sustainability: participatory resource management in Cambodian fishing villages, J. Environ. Manage., 90, 206-216, 2009.

Meijninger, W. M. L. and Bruin, H. R. A.: The sensible heat fluxes over irrigated areas in western Turkey determined with large aperture scintillometer, J. Hydrol., 229, 42-49, 2000.

Moriarty, P. B.: Integrated catchment management and sustainable water resource development in semi-arid Zimbabwe, $\mathrm{PhD}$ thesis, University of Reading, UK, 2000.

Rockström, J., Folke, C., Gordon, L., Hatibu, N., Jewitt, G., Penning de Vries, F., Rwehumbiza, F., Sally, H., Savenije, H., and Schulze, R.: A watershed approach to upgrade rainfed agriculture in water scarce regions through Water System Innovations: an integrated research initiative on water for food and rural livelihoods in balance with ecosystem functions, Phys. Chem. Earth, 29, 1109-1118, 2004.

Sally, H.: Final SSI Report: Strategies of water for food and environmental security in drought-prone tropical and sub-tropical agro-ecosystems, IWMI, Colombo and UNESCO-IHE, Delft, 2010.

Schulze, R. E., Schmidt, E. J., and Smithers, J. C.: PC-based SCS design flood estimates for small catchments in Southern Africa, Department of Agricultural Engineering, University of Natal, 1992.

Smith, H. J., Trytsman, G., Bloem, J. F., Everson, T., and Mthethwa, S.: Development and implementation of sustainable land management practices in the Bergville district of the KwaZulu-Natal Province, Fourth progress report, Emmaus Landcare project 2003/2004, Bergville, 2004

Sturdy, J. D., Jewitt, G. P. W., and Lorentz, S. A.: Building an understanding of water use innovation adoption processes through farmer-driven experimentation, Phys. Chem. Earth, 33, 859-872, 2008.

Wagener, T., Sivapalan, M., Troch, P. A., McGlynn, B. L., Harman, C. J., Gupta, H. V., Kumar, P., Rao, P. S. C., Basu, N. B., and Wilson, J. S.: The future of hydrology: an evolving science for a changing world, Water Resour. Res., 46, W05301, doi:10.1029/2009WR008906, 2010.

Wigmosta, M. S. and Burges, S. J.: An adapative modeling and monitoring approach to describe the hydrologic behavior of small catchments, J. Hydrol., 202, 48-77, 1997. 